\title{
Fabrication of a Zinc Aluminum Oxide Nanowire Array Photoelectrode for a Solar Cell Using a High Vacuum Die Casting Technique
}

\author{
Chin-Guo Kuo, ${ }^{1}$ Jung-Hsuan Chen, ${ }^{2}$ and Yueh-Han Liu ${ }^{1}$ \\ ${ }^{1}$ Department of Industrial Education, National Taiwan Normal University, Taipei 10610, Taiwan \\ ${ }^{2}$ Material and Chemical Research Laboratories, Industrial Technology Research Institute, Hsinchu 31040, Taiwan \\ Correspondence should be addressed to Jung-Hsuan Chen; jhc2369@yahoo.com.tw
}

Received 7 March 2014; Accepted 14 April 2014; Published 6 May 2014

Academic Editor: Chao-Rong Chen

Copyright (C) 2014 Chin-Guo Kuo et al. This is an open access article distributed under the Creative Commons Attribution License, which permits unrestricted use, distribution, and reproduction in any medium, provided the original work is properly cited.

Zinc aluminum alloy nanowire was fabricated by the vacuum die casting. Zinc aluminum alloy was melted, injected into nanomold under a hydraulic pressure, and solidified as nanowire shape. Nanomold was prepared by etching aluminum sheet with a purity of $99.7 \mathrm{wt} . \%$ in oxalic acid solution. A nanochannel within nanomold had a pore diameter of $80 \mathrm{~nm}$ and a thickness of $40 \mu \mathrm{m}$. Microstructure and characteristic analysis of the alumina nanomold and zinc-aluminum nanowire were performed by scanning electron microscope, X-ray diffraction analysis, and energy dispersive X-ray spectroscopy. Zinc aluminum oxide nanowire array was produced using the thermal oxidation method and designed for the photoelectrode application.

\section{Introduction}

Fossil fuels have the finite resources that will eventually dwindle and make too environmental damages to retrieve. As time goes on, they will become too expensive to utilize. Therefore, the development of the renewable energy, such as solar energy and wind, are necessary immediately.

Solar energy conversion is a highly attractive topic for clean and renewable power for the future. Dye sensitized solar cell (DSSC) is a type of Solar cell and has a significant potential to be a low cost alternative to conventional photovoltaic device. Various metal oxide nanostructures such as $\mathrm{TiO}_{2}, \mathrm{ZnO}, \mathrm{Fe}_{2} \mathrm{O}_{3}, \mathrm{ZrO}_{2}, \mathrm{Nb}_{2} \mathrm{O}_{5}, \mathrm{Al}_{2} \mathrm{O}_{3}$, and $\mathrm{CeO}_{2}$ have been successfully employed as photoelectrodes in SCs [111]. Among the above metal oxide nanostructures, $\mathrm{ZnO}$ draws much attraction for its particular properties. $\mathrm{ZnO}$ is a direct wide bandgap semiconductor $\left(E_{g}=3.4 \mathrm{eV}\right)$ with large exciton binding energy $(\sim 60 \mathrm{meV})$. The efficiency of a DSSC is strongly dependent on the charge recombination at the interface. The injected electron can be recaptured by the dye before diffusing into the bulk causing the losses of efficiency. The interfacial recombinations can be retarded by coating a thin layer of a second insulator, such as $\mathrm{Al}_{2} \mathrm{O}_{3}$
[12]. Similar results are also demonstrated by Palomares et al. [13]. Palomares and his coworkers state that the conformal growth of an overlayer of $\mathrm{Al}_{2} \mathrm{O}_{3}$ on a nanocrystalline $\mathrm{TiO}_{2}$ film would result in a 4 -fold retardation of interfacial charge recombination and a $30 \%$ improvement in photovoltaic device efficiency.

Therefore, it is supposed that zinc aluminum oxide nanowire would have better efficiency than zinc oxide nanowire and be a promising candidate for highly efficient SCs. Until now, few literatures mentioned the fabrication or synthesis of zinc aluminum oxide nanowire. The purpose of the research reported here was to propose a novel method to fabricate zinc aluminum oxide nanowire and apply the nanowires in the photoelectrode for DSSCs. Most important benefits of this method are the composition of nanowire could be controlled precisely and it is also easy to adjust the component.

\section{Experimental Procedure}

In this study, zinc aluminum oxide nanowires were fabricated using anodic aluminum oxide (AAO) as a template. The experimental procedure could divide into four parts. First of 
all, an anodic alumina nanomold was obtained by etching a pure aluminum sheet with a purity of $99.7 \mathrm{wt} . \%$ in $0.3 \mathrm{M}$ oxalic acid solution. Two steps of anode treatments were applied to obtain more uniform nanopores in this experiment. The first step of the anode treatment was carried out at a voltage $40 \mathrm{~V}$ and a temperature of $25^{\circ} \mathrm{C}$ for one hour. Afterward removing alumina thin film from the surface of aluminum sheet was performed in the mixture of $6 \%$ phosphoric acid solution and $2 \%$ chromic acid solution at a temperature of $60^{\circ} \mathrm{C}$. The second step of the anode treatment was carried out in the same process conditions indicated in the first step for 6 hours. Finally, aluminum substrate was removed using copper chloride solution and then the anodic alumina nanomold with a pore diameter of $80 \mathrm{~nm}$ could be obtained. Since the alumina membrane has an excellent chemical stability and could maintain its porous structure under the high temperature and pressure conditions, it is a very suitable mold $[14,15]$.

The second part of the procedure was the fabrication of zinc-aluminum alloy by the vacuum melting method. The high purity of zinc and aluminum scraps were mixed and placed in a quartz glass tube. In order to prevent metal from oxidation during melting, the vacuum was extracted using a molecular turbo pump and kept at $3 \times 10^{-6}$ torr. Then, the glass tube was placed in a furnace and the temperature was increased to $750^{\circ} \mathrm{C}$ for several minutes until all metal is smelted and mixed well. After cooling, zinc-aluminum alloy was obtained. More detailed process of the vacuum melting was described in our previous study [16, 17].

Furthermore, zinc-aluminum alloy nanowire array was produced using thehigh vacuum die casting technique. A piece of zinc-aluminum alloy and an alumina template were placed inside the chamber in which the vacuum pressure was maintained at $10^{-6}$ torr. After the chamber was heated to $750^{\circ} \mathrm{C}$, a hydraulic force was applied to the molten zinc-aluminum alloy. During casting, the molten alloy was injected into the anodic alumina nanomold forming alloy nanowire array. The force required to introduce molten alloy into the nanomold is proportional to the surface tension of the melt. The surface tension of the molten zinc at $750^{\circ} \mathrm{C}$ is 719.7 dyne $/ \mathrm{cm}$ and the surface tension of the molten aluminum at $750^{\circ} \mathrm{C}$ is 857.05 dyne $/ \mathrm{cm}$ [18]. Therefore, the surface tension of the molten zinc-aluminum ally at $750^{\circ} \mathrm{C}$ is 748.82 dyne/cm by calculation. Additionally, the pressure for the molten metal injection into nanomold can be evaluated as [19] $P=F / A=-(2 \gamma \cos \theta) / r$, where $F$ is the normal force, $A$ is the area of the nanomold, $r$ is the radius of the nanochannel, $\gamma$ is the surface tension of the molten zinc-aluminum alloy, and $\theta$ is the contact angle between the melt and the porous alumina membrane. The surface tension of the molten zincaluminum is 748.82 dyne $/ \mathrm{cm}$ and the contact angle is $104.85^{\circ}$. Therefore, the force required to inject the molten alloy into nanomold is $3.01 \times 10^{8}$ dyne. Solidification proceeded using a water cooling method at the bottom of the chamber. The zincaluminum nanowire array was formed after cooling to room temperature.

Finally, zinc aluminum oxide nanowire array was fabricated through a thermal oxidation process. The fabrication

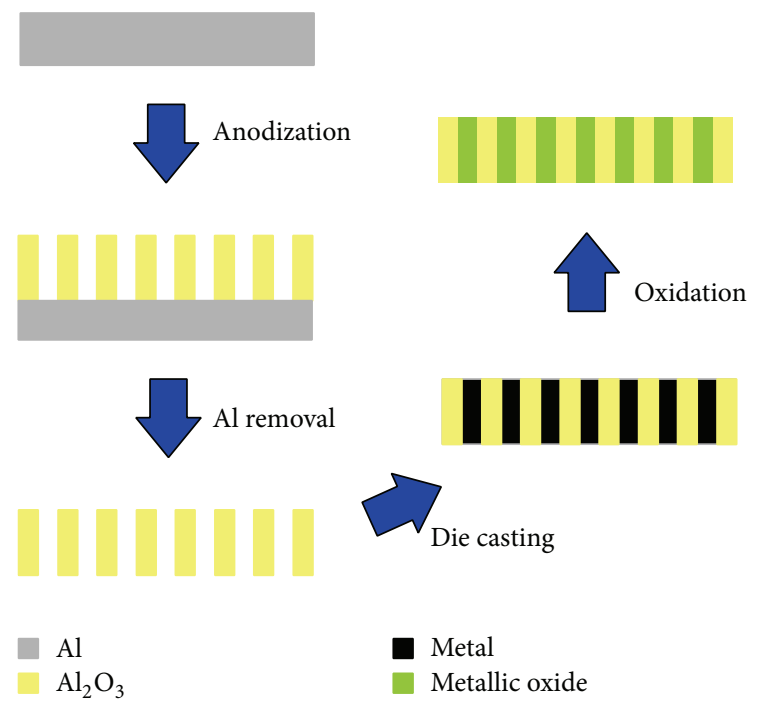

FIgURE 1: Schematic diagram of the zinc aluminum oxide nanowire array fabricated in this work.

procedure of zinc aluminum oxide nanowire array is illustrated in Figure 1. The nanowire array was put into an air furnace and applied a heat treatment at $250^{\circ} \mathrm{C}$ for 24 hours. After that, the aluminum oxide surrounding the nanowire was removed using sodium hydroxide solution and then zinc aluminum oxide nanowire array could be obtained.

The morphologies and the dimensions of the anodic alumina nanomold and the zinc aluminum nanowire array were observed by scanning electron microscope (SEM). The composition and crystallinity of the zinc-aluminum alloy nanowires were detected by X-ray diffraction (XRD) spectrum and energy dispersive spectroscopy (EDS). Differential scanning calorimeter (DSC) was used to measure the thermal characteristics of zinc-aluminum alloy.

\section{Results and Discussion}

In this study, porous alumina nanomold was produced using the anodization method with a two-step process in oxalic acid solution. The porous alumina nanomold was formed on aluminum with the equilibrium of oxide dissolution at the interface of the alumina/electrolyte and oxide grown at the metal/alumina interface [18]. Figures $2(a)$ and 2(b) are the morphologies of the anodic alumina membrane prepared in $0.3 \mathrm{M}$ oxalic acid solution for 6 hours. SEM images of the porous alumina membrane reveal that the nanopores with a diameter of $80 \mathrm{~nm}$ and a thickness $40 \mu \mathrm{m}$ are ordered and uniform arrays.

When metal smelts under a high temperature or the temperature higher than its melting point, metallic vapor volatilizes and causes the loss of the composition. In our study, zinc has a larger vapor pressure $\left(\sim 2 \times 10^{4} \mathrm{~Pa}\right)$ at the temperature of $750^{\circ} \mathrm{C}$ than aluminum $\left(\sim 10^{-4} \mathrm{~Pa}\right)$ [20], and the loss of zinc would be more serious than aluminum. Therefore, it is necessary to compensate for the consumption of zinc to maintain the final composition of the prepared alloy 


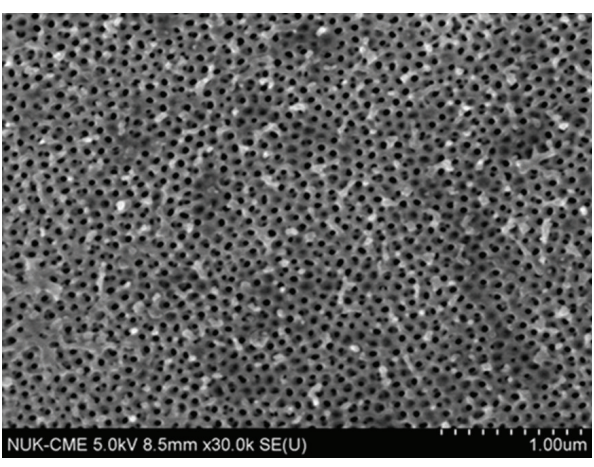

(a)

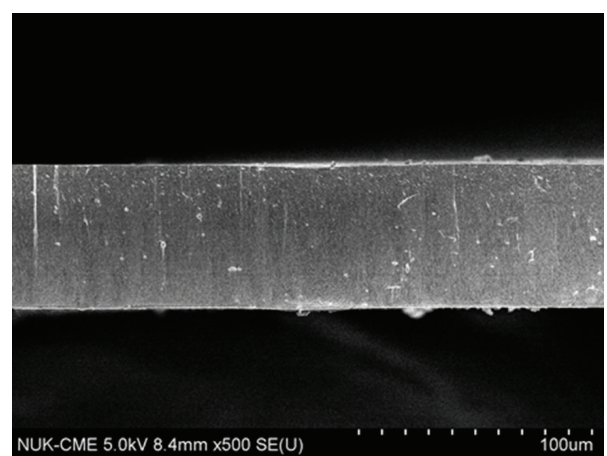

(b)

FIGURE 2: SEM images: (a) a porous alumina membrane with an ordering pore diameter of $80 \mathrm{~nm}$ and (b) the thickness of the porous alumina membrane was measured as $40 \mu \mathrm{m}$ from the cross-section image.

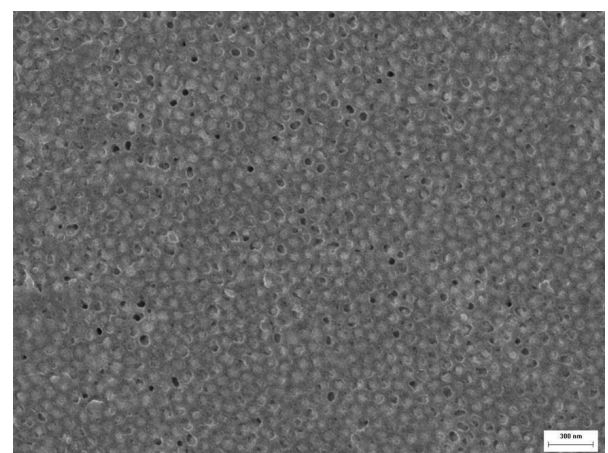

FIGURE 3: SEM images of zinc aluminum alloy nanowire arrays. Zinc aluminum nanowire array was fabricated in the alumina nanomold by the vacuum die casting process.

with the desired proportion. By the aid of the thermodynamic calculation, 90 wt.\% zinc- $10 \mathrm{wt} \%$ aluminum alloy could be produced precisely.

Using vacuum die casting technique, the molten zincaluminum alloy was introduced into the alumina nanomold and then forming zinc-aluminum alloy nanowire array. Figure 3 shows that the zinc-aluminum nanowires with the diameter of $80 \mathrm{~nm}$ exhibit the uniform distribution and have the high filling ratio. EDS results display that the percentage of zinc is $89.71 \mathrm{wt} . \%$, whereas the percentage of aluminum is $10.29 \mathrm{wt} . \%$. In addition, the result of XRD analysis of zinc aluminum nanowires is shown in Figure 4. The diffraction pattern proves the crystal structure and identifies the composition of alloy as theoretical composition. Figure 5 shows that the melting temperature of the zinc-aluminum alloy is $418.03^{\circ} \mathrm{C}$ obtained by DSC measurement. The melting point of the alloy is consistent with that indicated in the zinc aluminum binary alloy phase diagram [21].

Au thin film was deposited at the top surface of zinc aluminum oxide nanowires array as the conductive layer of the photoelectrode by vapor deposition technique. After that, the fabrication of the nanowire array photoelectrode was completed. Figure 6 is the schematic diagram of the nanowire array photoelectrode produced in the present study. For this

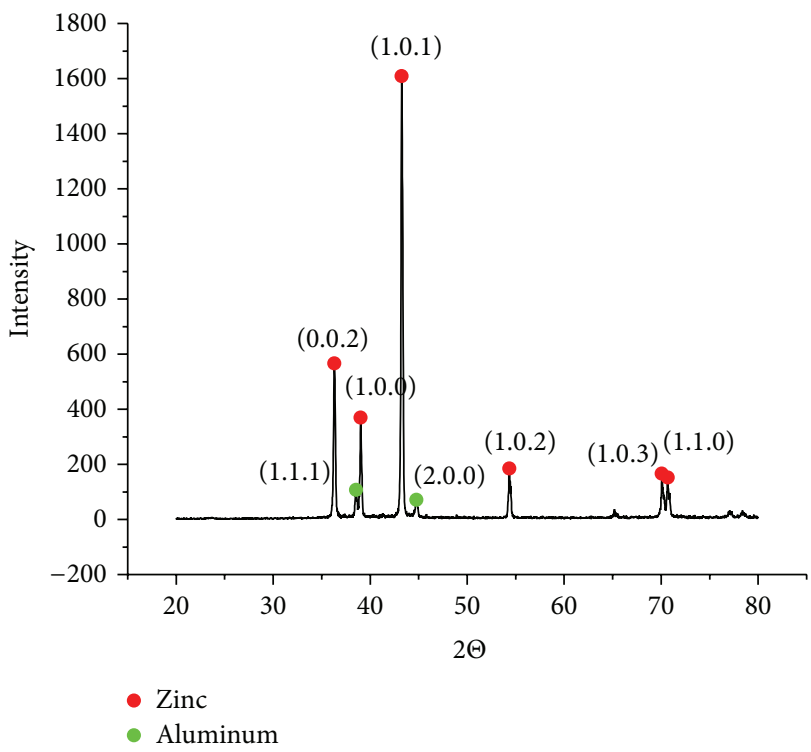

FIGURE 4: X-ray diffraction profiles of zinc-aluminum alloy composed of $90 \mathrm{wt} . \%$ zinc and $10 \mathrm{wt} . \%$ aluminum.

kind of photoelectrode, an ordered topology would increase the rate of electron transport and a nanowire electrode may improve the quantum efficiency of DSSCs depending on achieving the higher dye loadings through an increase in surface area. Therefore, the high aspect ratio zinc aluminum oxide photoelectrode designs for nanostructured semiconductor photoelectrodes in photoelectrochemical cells would be expected to enhance the attainable solar energy conversion efficiencies.

\section{Conclusions}

The present study provided a novel method to produce zinc-aluminum alloy nanowire with $80 \mathrm{~nm}$ in diameter and $40 \mu \mathrm{m}$ in length. The vacuum die casting applied a hydraulic pressure to inject the molten zinc-aluminum into the anodic alumina nanomold and then obtained zinc-aluminum alloy 


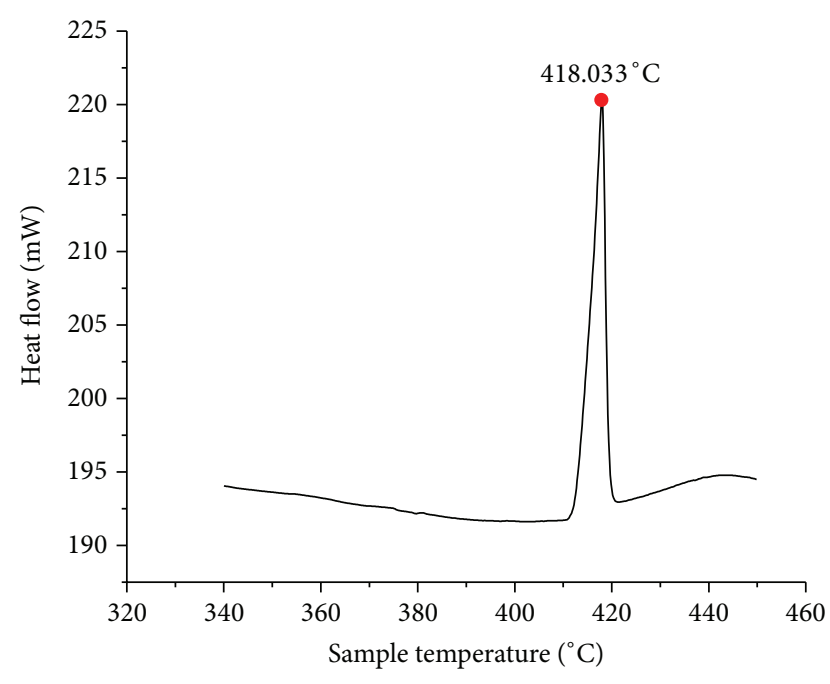

FIGURE 5: DSC thermographs of zinc-aluminum alloy composed of $90 \mathrm{wt} . \%$ zinc and $10 \mathrm{wt} . \%$ aluminum.

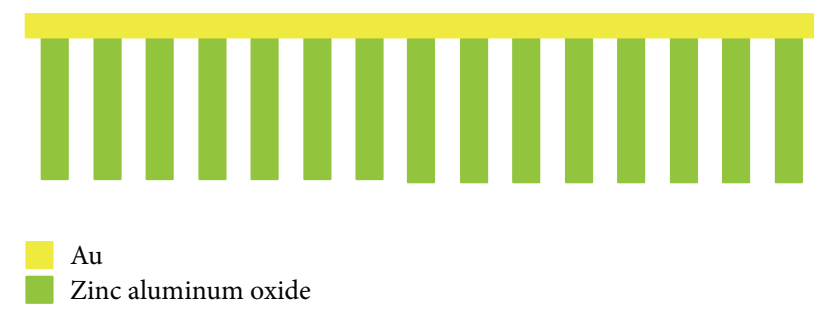

FIGURE 6: Schematic diagram of the prepared zinc aluminum oxide nanowire array photoelectrode.

nanowire after solidification. XRD and DSC results showed that zinc-aluminum alloy prepared in this work was a hypereutectic structure in which the weight percentage of zinc was $89.71 \%$ and the weight percentage of aluminum was $10.29 \%$. Using thermal oxidation technique, zinc aluminum oxide nanowire array was fabricated successfully. The order, uniform, and a large area of nanowire array were more suitable for device manufacture or other applications. In this study, zinc aluminum oxide nanowire array was applied as the photoelectrode of DSSCs.

\section{Conflict of Interests}

The authors declare that there is no conflict of interests regarding the publication of this paper.

\section{Acknowledgments}

The authors acknowledge the financial support of NSC 1023113-S-003-008-G and NSC 102-3113-S-262-001.

\section{References}

[1] N. O. V. Plank, M. E. Welland, J. L. MacManus-Driscoll, and L. Schmidt-Mende, "The backing layer dependence of open circuit voltage in $\mathrm{ZnO} /$ polymer composite solar cells," Thin Solid Films, vol. 516, no. 20, pp. 7218-7222, 2008.

[2] M. Q. Lv, D. J. Zheng, M. D. Ye et al., "Densely aligned rutile $\mathrm{TiO}_{2}$ nanorod arrays with high surface area for efficient dyesensitized solar cells "” Nanoscale, vol. 4, pp. 5872-5879, 2012.

[3] J. E. Boercker, J. B. Schmidt, and E. S. Aydil, "Transport limited growth of zinc oxide nanowires," Crystal Growth and Design, vol. 9, no. 6, pp. 2783-2789, 2009.

[4] M. Cavas, P. K. Gupta, A. A. Al-Ghamdi, Z. H. Gafer, F. ElTantawy, and F. Yakuphanoglu, "Preparation and characterization of dye sensitized solar cell based on nanostructured $\mathrm{Fe}_{2} \mathrm{O}_{3}$," Materials Letters, vol. 105, pp. 106-109, 2013.

[5] P. Ramasamy, D. H. Lim, J. S. Kim, and J. W. Kim, "A general approach for synthesis of functional metal oxide nanotubes and their application in dye-sensitized solar cells," RSC Advances, vol. 4, pp. 2858-2864, 2014.

[6] M. Kovendhan, D. P. Joseph, P. Manimuthu et al., "Spray deposited $\mathrm{Nb}_{2} \mathrm{O}_{5}$ thin film electrodes for fabrication of dye sensitized solar cells," Transactions of the Indian Institute of Metals, vol. 64, no. 1-2, pp. 185-188, 2011.

[7] N. Jeon and D. W. Kim, "Dye-sensitized solar cells assembled with composite gel polymer electrolytes containing nanosized $\mathrm{Al}_{2} \mathrm{O}_{3}$ particles," Journal of Nanoscience and Nanotechnology, vol. 13, pp. 7955-7958, 2013.

[8] H. Yu, Y. Bai, X. Zong, F. Q. Tang, G. Q. M. Lu, and L. Z. Wang, "Cubic $\mathrm{CeO}_{2}$ nanoparticles as mirror-like scattering layers for efficient light harvesting in dye-sensitized solar cells," Chemical Communications, vol. 48, pp. 7386-7388, 2012.

[9] H. Chang, K.-C. Cho, C.-G. Kuo et al., "Application of a Schottky barrier to dye-sensitized solar cells (DSSCs) with multilayer thin films of photoelectrodes," Journal of Alloys and Compounds, vol. 509, no. 1, pp. S486-S489, 2011.

[10] M. J. Kao, H. Chang, C. G. Kuo, K. D. Huang, and Y. L. Chen, "Fabrication and characterization of photoelectrode thin films with different morphologies of $\mathrm{TiO}_{2}$ nanoparticles for dyesensitized solar cells," Journal of Nanoscience and Nanotechnology, vol. 11, pp. 7459-7462, 2011.

[11] M. J. Kao, H. Chang, K. C. Cho, C. G. Kuo, S. H. Chien, and S. S. Liang, "Analysis of the electron transport properties in dyesensitized solar cells using highly ordered $\mathrm{TiO}_{2}$ nanotubes and $\mathrm{TiO}_{2}$ nanoparticles," Journal of Nanoscience and Nanotechnology, vol. 12, pp. 3515-3519, 2012.

[12] M. Law, L. E. Greene, A. Radenovic, T. Kuykendall, J. Liphardt, and P. Yang, " $\mathrm{ZnO}-\mathrm{Al}_{2} \mathrm{O}_{3}$ and $\mathrm{ZnO}-\mathrm{TiO}_{2}$ core-shell nanowire dye-sensitized solar cells," Journal of Physical Chemistry B, vol. 110, no. 45, pp. 22652-22663, 2006.

[13] E. Palomares, J. N. Clifford, S. A. Haque, T. Lutz, and J. R. Durrant, "Slow charge recombination in dye-sensitised solar cells (DSSC) using $\mathrm{Al}_{2} \mathrm{O}_{3}$ coated nanoporous $\mathrm{TiO}_{2}$ films," Chemical Communications, no. 14, pp. 1464-1465, 2002.

[14] S. Shingubara, "Fabrication of nanomaterials using porous alumina templates," Journal of Nanoparticle Research, vol. 5, no. 1-2, pp. 17-30, 2003.

[15] Y. T. Pang, G. W. Meng, L. D. Zhang et al., "Arrays of ordered Pb nanowires and their optical properties for laminated polarizers," Advanced Functional Materials, vol. 12, pp. 719-722, 2002.

[16] C. G. Kuo, H. Chang, L. R. Hwang et al., "Fabrication of a Pb-Sn nanowire array gas sensor using a novel high vacuum die casting technique," Electronic Materials Letters, no. 9, pp. 481-484, 2013.

[17] J.-H. Chen, S.-C. Lo, C.-G. Chao, and T.-F. Liu, "Microstructure and properties of $\mathrm{Pb}$ nanowires fabricated by casting," Japanese Journal of Applied Physics, vol. 47, no. 6, pp. 4815-4819, 2008. 
[18] I. S. Grigoriev and E. Z. Meilikhov, Handbook of Physical Quantities, CRC Press, Boca Raton, Fla, USA, 1997.

[19] Z. Zhang, J. Y. Ying, and M. S. Dresselhaus, "Bismuth quantumwire arrays fabricated by a vacuum melting and pressure injection process," Journal of Materials Research, vol. 13, no. 7, pp. 1745-1748, 1998.

[20] O. Jessensky, F. Müller, and U. Gösele, "Self-organized formation of hexagonal pore arrays in anodic alumina," Applied Physics Letters, vol. 72, no. 10, pp. 1173-1175, 1998.

[21] W. R. Osório, C. M. Freire, and A. Garcia, "The effect of the dendritic microstructure on the corrosion resistance of $\mathrm{Zn}-\mathrm{Al}$ alloys," Journal of Alloys and Compounds, vol. 397, no. 1-2, pp. 179-191, 2005. 

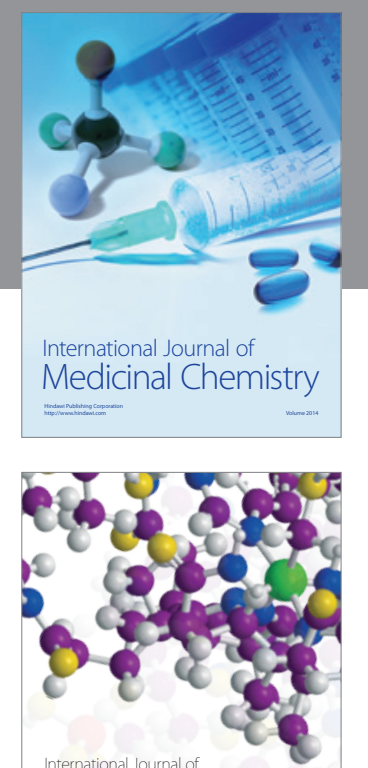

\section{Carbohydrate} Chemistry

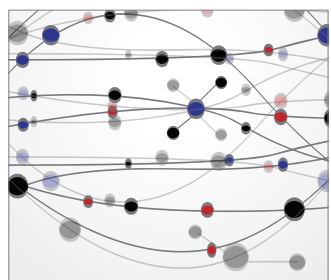

The Scientific World Journal
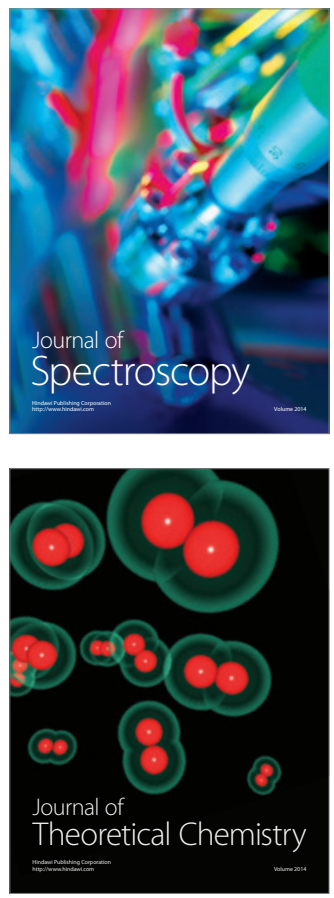
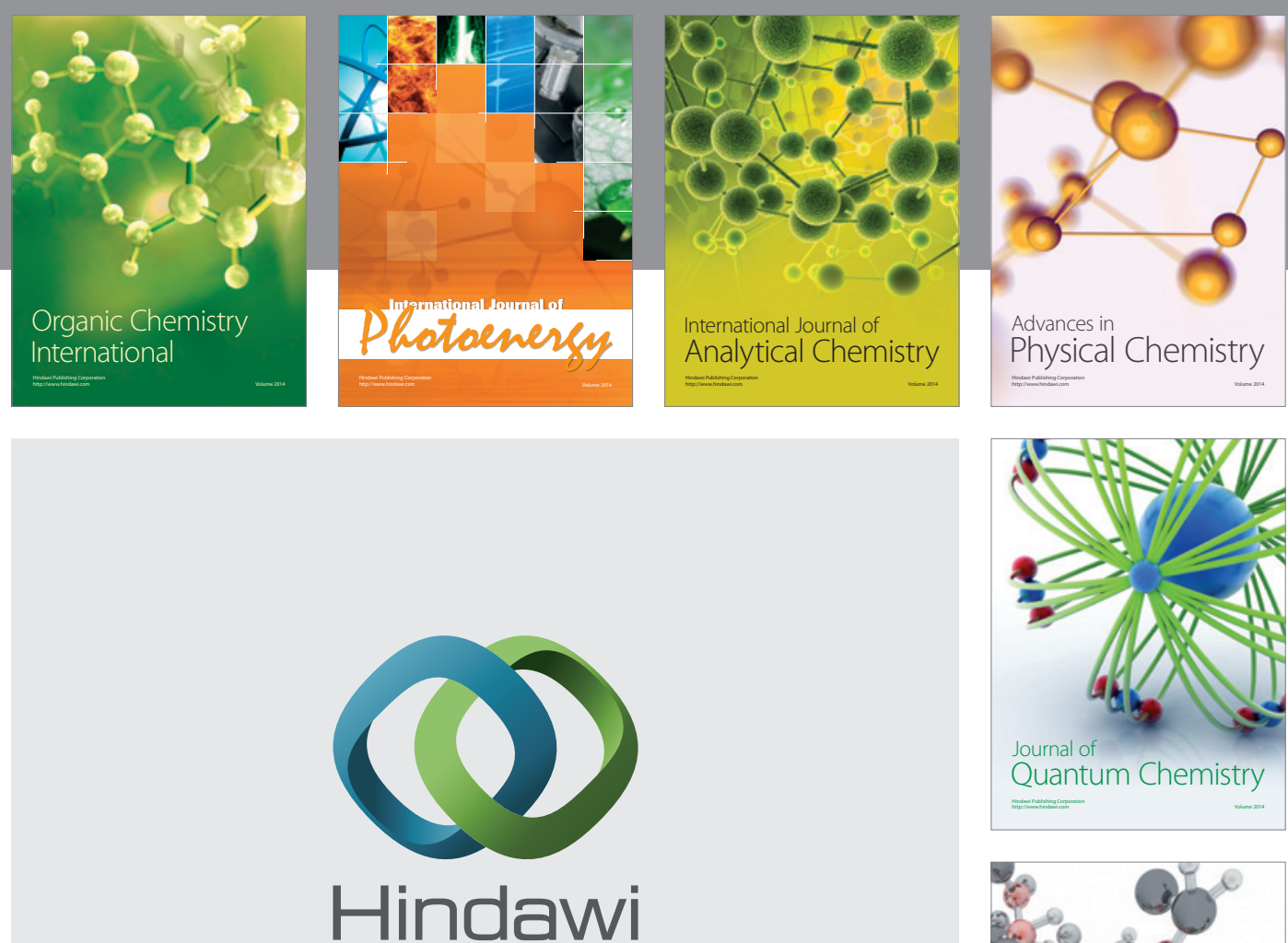

Submit your manuscripts at

http://www.hindawi.com

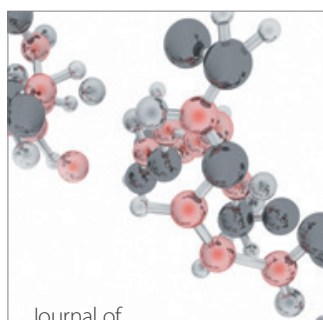

Analytical Methods

in Chemistry

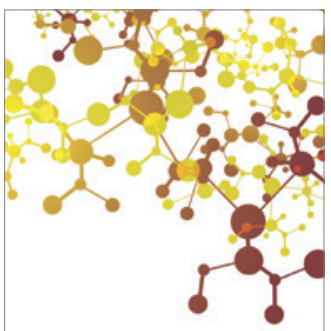

Journal of

Applied Chemistry

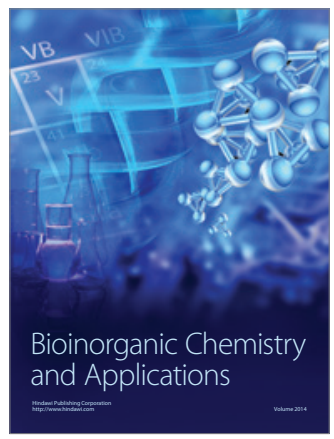

Inorganic Chemistry
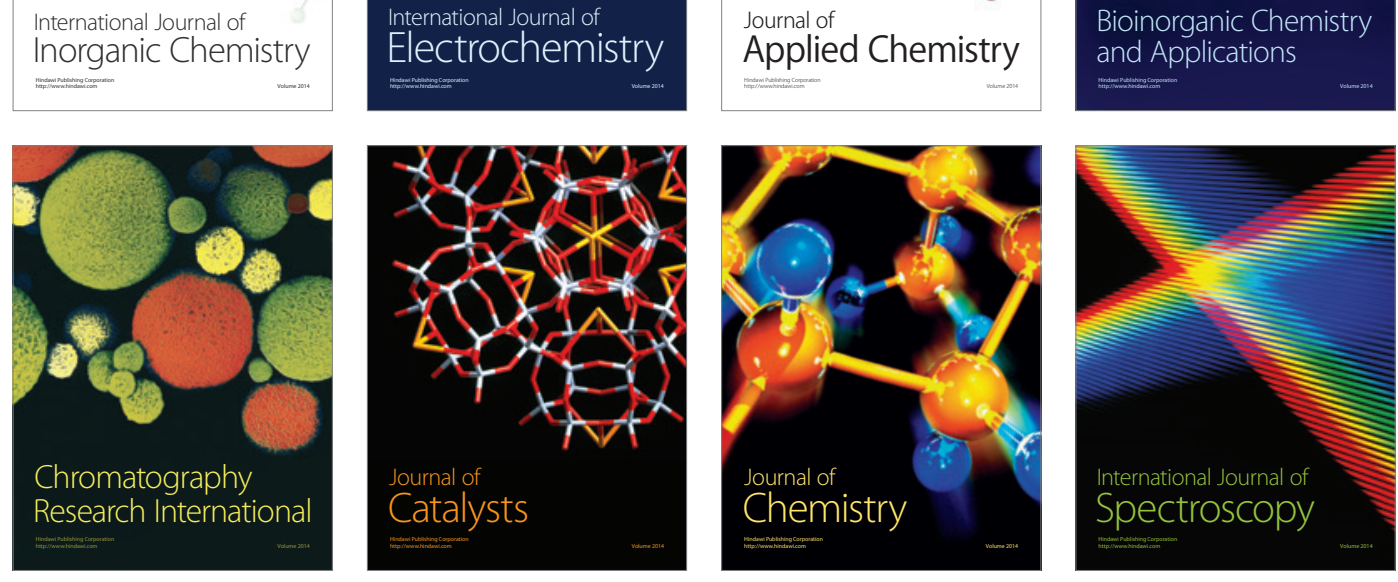